\title{
A Comparative Study of Throw Subtype in Motion Verbs Based on Dixon's Theory in English and Buginese
}

\author{
Rahmaniar $^{1 *}$ \\ ${ }^{1}$ Department of English Language Studies, Universitas Hasanuddin, Makassar, Indonesia \\ *rahmaniarmaros@gmail.com
}

\begin{abstract}
This research focuses on Throw Subtype verbs in English and Buginese in investigating similarities and differences of motion verbs, and identifying them in the semantic aspect and grammatical construction. This research data, English data collected from Corpus of Contemporary American English (COCA) and Buginese data obtained from field research through observation process and interview, are analyzed with descriptive and qualitative analysis. The research results indicate (1) Thirteen Throw Subtype verbs in English: throw, chuck, fling, pour, spray, water, push, press, pull, jerk, drag, tug, and draw. Then, nineteen of those in Buginese: makkabeang, mademperrang, mangappeyang, maggampessang, mappalitta', mappattama', mattiri, mattuppa', massimporo', massirang, massorong, massogorang, mappagappo, mattenre', marrui', maddui', mappasitta', madduisang, and marenreng. In Buginese verbs, several verb types implies the same meaning in English verbs but in different usage. makkabeang, mademperrang, mangappeyang and maggampessang have a similar meaning with 'throw' verb. Next, mattiri and mattupa have the same meaning with 'water' verb. Then, massorong, massogorang, mappagapo have the similar meaning with 'push' verb All those verbs are categorized as transitive verb (2) The main differences of Throw subtypes in English and Buginese language can be seen from clause structure. Clause structure of Buginese is similar to English where NP is followed by $\mathrm{VP}$ since all verbs are known as intransitive construction. However, it has six patterns-NP+VP, NP+VP+ADV, $\mathrm{VP}+\mathrm{NP}, \mathrm{VP}+\mathrm{NP}+\mathrm{ADV}, \mathrm{ADV}+\mathrm{VP}+\mathrm{ADV}, \mathrm{NP}(\mathrm{Ob})+\mathrm{VP}+\mathrm{ADV}$. Regarding preposition, two prepositions in Buginese have similar meaning and difference usage such as ri/di, and ku which mean in.
\end{abstract}

Key words: Catch verb, clause structure, semantic types.

\section{Introduction}

As social beings, human always communicates with other human beings. Communication is an event in which humans express their feelings or express their desire to other people. The term good communication is when the listener or reader is able to determine the intention of the speaker or writer well.

Linguistics is defined as the science of language or the scientific study of language. In linguistics, language is traditionally seen as consisting of three parts, those are signs, meanings, and codes connecting signs with their meanings. The part of linguistics that deals with how signs can be combined to form words, phrases, and sentences 
is called syntax. Whereas, Semantics deals with the meanings (what is signified, while the three levels: phonology, morphology and syntax concerned with the exponent [1].

Grammar is a set of rules that define how words (or parts of words) are combined or changed to form acceptable units of meaning within a language [2]. Grammar comprises the rules that show how words are combined, arranged or changed to show certain kinds of meaning [3]. Semantics is considered as a branch of linguistics which related to the meaning [4].

Motion is the actual movement or activating process. Different languages offer different means of conveying how motion is expressed. Motion verbs are verbs used commonly in human daily actions and their meaning refer to verbs showing the motion such as run, take, carry and throw. The use of motion verbs is closely related to preposition, e.g. William ran in the football field, I walked in the street, I went to Jakarta.

Verbs consist of motion verb, rest verb, affect verb, and giving verb [5]. Furthermore, motion verbs are verbs used commonly in human daily actions and their meaning refer to verbs showing the motion such as carry, pull, throw, push and fall. Then, this motion also related to preposition for example: I carry some snack to you, you throw the rubbish in the canal, you pull the door. He also recognizes formulation theory of semantic from semantic approach of English where word and grammar are totally related to semantic. The contribution of his theory takes a part of comparing the meaning contained in a language because there are some differences in equivalent meaning each other. Its contribution itself becomes the reason for his theory to be re-studied. Furthermore, he declares that throw subtype describes causing something to be in motion. These verbs are all transitive. The moving role is mapped onto the subject and the causer which need not be moving in the subject slot. The meanings of individual verbs describe both the mode of motion and the way in which it was caused. As with Run subtype a specification of Locus is possible, but quite optional, e.g. Mary pushed the table (from the wall into the middle room) and John threw the ball (towards the grandstand).

Therefore, the researcher is to focus on the rest verbs based on Open Subtype in Buginese. The reason for conducting this research is based on the preliminary research done where there are difference meanings of motion verb in Buginese. For example, in rest verbs based on Throw Subtype have eighteen verbs based on the semantics meaning. Buginese is one of the local languages in South Sulawesi [6].

\section{Theoretical Reviews}

There are some brief outlines of previous studies which are related to the current study. In the motion verbs comparison in English and Wolio Language, there are 81 motion verbs found in English and 85 motion verbs in Wolio language. Some verbs of English 'Run' subtype can be used in causative sense. Whereas, almost all motion verbs of Wolio 'Run' subtype are intransitive verbs. Only some of them can be used in causative sense when they are added with certain prefix or when certain prefix attached to the verbs is omitted [7].

Meanwhile, English and Buginese affect verbs have equivalences and differences. Cultural background plays important role in determining variants of the verb. New feature of stretch subtype is Agent in using Manip to change the taste of the target. Buginese verbs included in those new features are fejei (put salt in), fissingi (put monosodium glutamate in), santangi (put coconut milk in), fellengi (put candle nut in) and cempai (put tamarind in) [8]. English and Barru Buginese show the meaning differences in relation to motion verbs of Carry subtype, especially on the clause structure and preposition [9].

The clause structure in verb (or a verb phrase) as long as the subject is plainly comprehensible from the previous discourse or context. Meanwhile, in aspect of preposition in Buginese, there are two prepositions that have similar meaning and different use, such as ri and ku [10].

A review of Dixon's giving semantic type theoretical framework analyzed the construction and the extended meaning of English 'give' verb and kasi verb in Kupang language. It find out that the basic constructions of both languages are same, but different in grammatical properties that result to different meaning [11]. The 'recipient' and 'donor' could be omitted when an adverb such as out, away, and back is added to 'give' verb. Indicating general giving activity, in Kupang Malay, a verb and noun can be added in kasi verb. In the construction, all the roles can be either omitted or stated. The literal meaning of both verbs can extent to grammatical meaning metaphorically, but 'give' verb exhibit more variation. The different of historical development of language and sociolinguistic characteristic of 'give' verb and kasi verb become the reason of the phenomenon happened.

An identification of Rest verbs in English and Buginese based on the divided Sit subtype revealed nine rest verbs of Sit subtype in English, including sit (down), stand (up), lie (down), kneel, crouch, squat, lean, hang (down), and float, while in Buginese, there are twenty eight Sit subtypes: tudang, cadok, cadok-cadok, se'ppok, me'ppok, massampiang, massulekka, se'ppok, makkaddao uttu, mattulak sadang, mappasilojo', mappalempuk, massollasolla, mattafakkoro, massale'poro, maddue'due', tettong, le'ngeng, llEu, makkanroppang, mappatettong uttuk, makkaluttu, cukuk, rroko', sujuk, maccekkeng, ssanrE', maggattung, and mmawang [12]. In contrast, English Verb "Fall", for instance, shows differences with Makassarese language in Drop subtype in terms of grammatical constructions [13]. 
English constructions mostly are started by subject or something as causer slot which is followed by fall as verb without noun phrase as moving object because "fall" verb in English categories as intransitive verb. The locus slot is marked by preposition. While in Makassarese language, the constructions mostly are started by fall as verb, subject in causer slot, noun phrase as moving object and locus slot that is marked by preposition.

The method is written descriptively and should describe the research methodology or steps in conducting the study. A brief justification of the method is recommended to give an idea to the reader about the appropriateness of the method, reliability and validity of the results.

\section{Methodology}

This researcher used a descriptive qualitative method in which the writer analyzed the data to compare between Motion verbs in English and Buginese; both in meaning aspect and in grammatical construction. Motion verbs in both languages were presented descriptively in the form of comparison. This research was in form of both field and library research. In collecting data, the writer listed English verbs and Buginese verbs which indicate Motion. Then the example of the verb usage of English and Buginese was obtained in different ways. English data was collected from Corpus of Contemporary American English (COCA), meanwhile Buginese data was gained from observation and in dept interview with people using Buginese data. Participant observation is a qualitative method with roots in traditional ethnographic research, whose objective is to help researchers learn the perspectives held by study populations. The Buginese data was collected from people using Buginese in Maros regency. The writer chooses Maros regency because she can understand well the typical Buginese language there and it makes her get easier to collect the data. In analyzing of the data, the writer used some techniques of analyzing data in order to answer the research questions. They are: 1) the data which had been collected were transcribed. The first step was transcribing Buginese data gained from observation and depth interview. Since English data were obtained from COCA, it did not need to be transcribed anymore, 2) the numbers of transcribed data were reduced by selecting the important and related data. Both English and Buginese data which have been collected were reduced by selecting data that could be representative of others, 3 ) the reduced data was presented. The next step was presenting the data. The data which had been reduced were presented based on Throw subtype divided by Dixon. Presentation of example of each motion verb was in the form of clause. English motion verbs came first and followed by Buginese motion verbs, 4) the data were then analyzed. The presented data were analyzed by applying Dixon's semantic principles, but in advance each clause was analyzed based on the word classes and semantic role. The writer used Oxford Dictionary to determine the meaning of English Motion verbs, whereas the meanings of Motion verbs in Buginese concluded based on the reading the context. The last, the writer resolved the grammatical properties of those Motion verbs underlain on their meanings as the starting point, and 5) conclusion was made. After doing the analysis, in the last step the writer made some conclusions which could reflect the main points of the analysis as the result of the study.

\section{Findings and Discussion}

There are thirteen motion verbs categorized in Throw subtype of English. They are throw, chuck, fling, pour, spray, water, push, press, pull, jerk, drag, tug, and draw, while in Buginese there are nineteen verbs of Throw subtype, they are makkabeang, mademperrang, mangappeyang, maggampessang, mappalitta', mappattama, mattiri, mattuppa', massimporo, massirang massorong, massogorang, mappagappo, mattenre', marrui', maddui', mappasitta', madduisang, and marenreng. The representations of 'throw' verbs are physical actions which are exerted by an agent's body part, namely hand or hands; hence the features of bodily action are the core of their meaning. In 'throw' verbs considered the force of the action, direction, force, and hand height. The moving role may be filled by either human or non-human and the noun phrase of locus is always specified by preposition.

The verb makkabeang has a slight meaning with throw in English verb which means throwing something effortless in slow motion. The moving role is always in the object slot and the causer in the subject slot. The subject may be added by the suffix of the verb. Maddemperrang means throwing something roughly and being usually done with quick motion. Next, Mangappeyang means throwing something a little hard and with a quick motion. Then, maggampessang means throwing something brutally and using two hands and usually can break things.

Chuck means to throw something carelessly. The moving role is always in the object slot and the causer is in the subject slot. Mappalitta' refers 'to chucking something with effort and quickly motion'. Verb fling refers to throwing something or someone suddenly and with a lot of force. Mappatama means 'to flinging something with effort with quick motion'. The moving and the causer roles are always in the object and subject slot respectively. The noun phrase locus marked by preposition is often specified.

Pour means to cause to flow in a stream/ to dispense from a container. Mattiri means 'to pouring something with little effort, usually need container to fill it, and just need a little capacity with slow motion'. Mattuppa' refers 'to poring something with hard effort and need widely space, big capacity then doing it fast motion'. Spray refers to a mass of very small drops of liquid carried in the air. Massimporo' refers 'to spraying something in widely area'. Water 
means pouring or sprinkle water over (a plant or area) in order to encourage plant growth. Massirang means pour small drops or particles of a substance over (an object or surface). The moving and the causer roles are always in the object and subject slot respectively. The noun phrase locus marked by preposition is often specified.

Push means exert force on (someone or something), typically with one's hand, in order to move them away from oneself or the origin of the force. Massorong refers 'to pushing something without slow, medium or hard effort'. Press means to move or cause to move into a position of contact with something by exerting continuous physical force. Mattenre' means 'to pressing something with effort depend on the case'. Pull means to exert force upon so as to cause or tend to cause motion toward the force. Marrui' means 'to pulling something with little effort'. The moving and the causer roles are always in the object and subject slot respectively. The noun phrase locus is often specified.

Jerk means to give a quick suddenly arrested push, pull, or twist to. Maddui' means 'to jerking something in hard effort'. Drag means pull (someone or something) along forcefully, roughly, or with difficulty. Mappasitta' means dragging something in roughly way. Tug means pull (something) hard or suddenly. Madduisang means tugging something in quickly motion. Draw means pull or drag (something such as a vehicle) so as to make it follow behind. Marenreng means drawing something in slowly motion. The moving and the causer roles are always in the object and subject slot respectively. The noun phrase locus is often specified.

The result of this research shows there are thirteen verbs indicating motion verbs of 'Throw' subtype in English, they are throw, chuck, fling, pour, spray, water, push, press, pull, jerk, drag, tug, and draw. In Buginese, there are nineteen verbs refer to motion verbs, they are makkabeang, mademperrang, mangappeyang, maggampessang, mappalitta', mappattama, mattiri, mattuppa', massimporo, massirang massorong, massogorang, mappagappo, mattenre', marrui', maddui', mappasitta', madduisang, and marenreng.

Based on the Buginese data shown in finding, there are five variations or patterns of constructions in Buginese as in the follow table:

Table 1. The Detail of ESL Writing Perception of Each Gender

\begin{tabular}{lll}
\hline No & Pattern & Verb \\
\hline 1 & NP + VP & Maddemperrang, maggampessang, assogorang, matenre \\
2 & NP+VP+ADV & Mangappeyang, mappatama, massimporo, massorong, madduisang, marenreng, mattuppa, mappalitta \\
3 & VP+NP & Mappagappo, maddui \\
4 & VP + NP + ADV & Makkabeang, mappasitta \\
5 & ADV+ VP + ADV & Mattuppa, massirang \\
6 & NP(Ob) +VP + ADV & Mattiri \\
\hline
\end{tabular}

From the table above shows that is general to not begin the sentence with noun Phrase (NP) as subject slot but with verb phrase (VP), or adverb (ADV). Most of the VP in Buginese sentence consist of prefix or suffix which reflect the subject pronoun of the sentence. They are prefix na- , ku-, u- and suffix -i, -ka, -na. Prefix na- reflects the third person singular pronoun of the sentence. Prefix ku- and $\mathrm{u}$ - reflects to the first-person singular pronoun. While suffix $-i$ and -na reflects third person singular pronoun of the sentence, and suffix -ka reflects first singular person pronoun of the sentence.

\section{Conclusion}

Based on the research result, the writer may conclude that there are thirteen motion verbs of 'Throw' subtype in English, they are throw, chuck, fling, pour, spray, water, push, press, pull, jerk, drag, tug, and draw. In Buginese, there are nineteen verbs refer to motion verbs, they are makkabeang, mademperrang, mangappeyang, maggampessang, mappalitta', mappattama, mattiri, mattuppa', massimporo, massirang massorong, massogorang, mappagappo, mattenre', marrui', maddui', mappasitta', madduisang, and marenreng.

The meaning differences between English throw subtypes and Buginese throw subtypes verbs the different grammatical construction. The main differences of motion verbs of Throw subtype in English and Buginese can be seen in clause structure. From clause structure, it can be found that basically clause structure of Buginese is similar with English in which it has noun phrase followed by a verb phrase since all the verbs of Throw subtype is in transitive construction. However, the clause structure in Buginese has some variations, those are: NP + VP, NP + VP+ ADV, $\mathrm{VP}+\mathrm{NP}, \mathrm{VP}+\mathrm{NP}+\mathrm{ADV}, \mathrm{ADV}+\mathrm{VP}+\mathrm{ADV}, \mathrm{NP}(\mathrm{Ob})+\mathrm{VP}+\mathrm{ADV}$. This current study applies semantic approach to analyze grammar of language. There are some other categories that are proposed by Dixon. This current study takes one that is "Catch" verb in Hold subtype. In the future, the writer expects that there will be another researcher who takes other subtype of Dixon to analyze or applies another local language to be compared to English. 


\section{Acknowledgement}

The researcher would like to thank the participants who have provided data and information for the purpose of this research.

\section{References}

[1] M. Kracht, Introduction to Linguistics. Department of Linguistics, UCLA: Lecturing Paper, 2008.

[2] R. Penny, Variation and change in Spanish. Cambridge: Cambridge University Press, 2000

[3] M. Swan, Practical English Usage, $3^{\text {rd }}$ Ed. Oxford: Oxford University Press, 2005

[4] P. Griffiths, An Introduction to English Semantics and Pragmatics. Scotland: Edinburgh University Press, 2006.

[5] R. M. W. Dixon, A Semantic Approach to English Grammar, 2 ${ }^{\text {nd }}$ Ed. New York: Oxford University Press, 2005.

[6] D. Tahir, F. Rahman, A. Rahman, "The Study of Buginese Reciprocal Verb in the Boegineesche Chrestomathies Manuscript," American Journal of Humanities and Social Sciences and Research (AJHSSR), Vol. 2, Issue 08, pp. 48-54, 2018.

[7] N. Melansari, "Motion Verbs in English and Wolio language: A Semantic Point of View," Unpublished Thesis, Postgraduate Program., Hasanuddin University., Makassar., South Sulawesi, 2015

[8] Fahruddin, "The Affect Verbs Subtypes in English And Buginese Language (semantical and syntactical perspective)," Thesis, Postgraduate Program., Hasanuddin University., Makassar., South Sulawesi, 2015.

[9] R. Apreliah R, "Dixon's Carry Subtype of motion Verbs in English and Barru Buginese," Unpublished Thesis, Postgraduate Program., Hasanuddin University., Makassar., South Sulawesi, 2016.

[10] Zulkhaeriyah, N. J. Saleh, A. H. Yassi, \& F. Rahman. (2021, June). "Strategy of Apology in Buginese: A Sociolinguistic Study". ELS Journal on Interdisciplinary Studies in Humanities [online]. Vol. 4 No. 2, pp. 188-196. Available: https://doi.org/10.34050/elsjish.v4i2.14015

[11] Suriati, "The Construction of 'give' verb in English and Kupang Malay based on Dixon's semantic theory," Thesis, Postgraduate Program., Nusa Lontar Rote University., East Nusa Tenggara., 2016.

[12] R. A. Hartari, "Dixon's Sit Subtype of Rest Verbs in English and Buginese," Unpublished thesis, Postgraduate Program., Hasanuddin University., Makassar., South Sulawesi, 2018.

[13] N. Wahidah, "English Verb, "Fall" and Its Related Verbs in Makassarese Language: A Comparative Study," Postgraduate Program., Hasanuddin University., Makassar., South Sulawesi, 2018. 